\title{
Seroprevalence of herpes simplex virus type 1 and type 2 in Thuringia, Germany, 1999 to 2006
}

A Sauerbrei (Andreas.Sauerbrei@med.uni-jena.de) ${ }^{1}$, S Schmitt ${ }^{2}$, T Scheper ${ }^{3}$, A Brandstädt ${ }^{4}$, S Saschenbrecker ${ }^{3}$, M Motz ${ }^{5}$, E Soutschek ${ }^{5}$, P Wutzler ${ }^{1}$

1. Institute of Virology and Antiviral Therapy, German Reference Laboratory for HSV and VZV, Jena University Clinic, Jena, Germany

2. SanofiPasteur MSD, Leimen, Germany

3. Institute of Experimental Immunology (affiliated to Euroimmun AG), Lübeck, Germany

4. Institute of Medical Statistics, Computer Sciences and Documentation, Jena University Clinic, Jena, Germany

5. Mikrogen, Neuried, Germany

Citation style for this article:

Sauerbrei A, Schmitt S, Scheper T, Brandstädt A, Saschenbrecker S, Motz M, Soutschek E, Wutzler P. Seroprevalence of herpes simplex virus type 1 and type 2 in Thuringia, Germany, 1999 to 2006.

Euro Surveill. 2011;16(44):pii=20005. Available online: http://www.eurosurveillance.org/ViewArticle.aspx?Articleld=20005

Article published on 3 November 2011

The prevalence of herpes simplex virus (HSV) typespecific IgG was determined in sera taken in 1999 to 2006 from 1,100 children aged $0-18$ years, 800 blood donors and 200 pregnant women in Thuringia, Germany, using tests based on the HSV glycoproteins (g) gG. By the age of 10-12 years, HSV-1 IgG prevalence reached $57.3 \%$, rising to $69.3 \%$ by the age of $16-18$ years and to $78.0 \%$ by the age of $28-30$ years. Between $2.7 \%$ and $4.7 \%$ of the children aged up to 15 years had HSV-2 antibodies, increasing to $7.3 \%$ at the age of $16-18$ years and to $13.6 \%$ among adults. The prevalence of HSV-1 antibodies among girls was significantly lower than among boys and a significantly higher prevalence of HSV-2 IgG in women than in men was detected. The reduced incidence of HSV-1 infections during childhood, especially in girls, has to be followed up since a higher number of primary HSV-2 infections may result. Between $2.7 \%$ and $4.7 \%$ of all children tested seemed to acquire HSV-2 by intrauterine or neonatal infection. We also compared the use of gG-1 with gC-1: the agreement of $97.2 \%$ between the two ELISAs suggests that gG-1 and gC-1 can be considered equivalent antigenic targets.

\section{Introduction}

Herpes simplex virus (HSV) is one of the most common pathogens affecting humans: it can remain latent lifelong in sensory ganglia and can be reactivated periodically. Infections may result in substantial physical and psychological morbidity. There are two types, HSV-1 and HSV-2, which differ not only genetically but also in the principal route of transmission, the body site predominantly affected, seroprevalence and rate of reactivation [1]. Both types are mainly transmitted by direct contact. In HSV-1 infection, the body above the waist is predominantly affected; in HSV-2, it is mainly below the waist. For HSV-1, primary infections occur mostly during infancy and childhood, after maternal antibodies have disappeared in the first year of life. In contrast, HSV-2 mainly affects adolescents and adults.
Excretion of the virus from herpetic lesions (mainly lips and genitals) in symptomatic people with recurrent infections and excretion of the virus in the saliva and genitals of asymptomatic people are regarded as the most important source of the virus [2].

Unlike HSV-1, HSV-2 is predominantly acquired through sexual activity [3] and causes the great majority of genital herpes [4]. In persons with past primary HSV-1 infection, the risk of acquiring HSV-2 is probably reduced since most antibodies cross-react between HSV-1 and HSV-2 [5]. Although no clinical signs can be recognised in many people with HSV-2 infections, as is also the case for HSV-1 infections, asymptomatic people can shed the virus, and thus there is a substantial risk of viral transmission to their sexual partners [6]. Even though the risk of vertical viral transmission is lower than that for acquiring primary infection, recurrent genital herpes must be regarded as the most common cause of neonatal infections [7]: up to $85 \%$ of neonatal herpes infections are caused by HSV-2 [8], which are associated with a poor prognosis [9].

HSV type-specific seroprevalence has been extensively studied in many countries all over the world. Seroprevalence rates of HSV-1 of between $50 \%$ and $85 \%$ or more have been shown in adults from developed countries, such as Germany, Spain and Norway, in the last two decades $[3,10]$. For HSV-2, seroprevalence varied as a function of age, sex, number of lifetime sexual partners and socio-economic status $[3,10]$. In Germany, the prevalence of HSV-1 IgG antibodies reached levels of more than 90\% in adults during 1996 to 1998 , whereas about $15 \%$ of adults possessed IgG antibodies to HSV-2 [10]. Further studies revealed that the prevalence of antibodies to both HSV types has not changed over the last two to three decades in Germany [11]. However, only a few studies have analysed the time of HSV seroconversion during infancy, childhood and adolescence. In particular, little is known about the 
seroprevalence of HSV-2 in children: seroprevalence in childhood is often used to estimate the incidence of intrauterine and neonatal HSV-2 infections. Recent studies have shown that nearly one third of children in Sweden [12] have been infected with HSV-1 and there is a gradual development of antibodies throughout childhood [3,12]. In contrast, HSV-2 antibodies have been reported to appear generally after sexual debut $[3,13]$.

The envelope glycoproteins (g) G of HSV-1 (gG-1) and HSV-2 (gG-2) are known to be type-specific antigens [14] and have been used in nearly all conclusive HSV-1 and HSV-2 seroprevalence studies [3]. Recently, gC-1 was shown to be an equivalent antigenic target for type-specific diagnosis of HSV-1 infections [15].

As there are few data on the prevalence of HSV antibodies in Germany, we carried out a seroepidemiological study to determine the HSV-1 and HSV-2 antibody prevalence in children, adults and pregnant women in the German federal state of Thuringia. For detection of HSV-1-specific antibodies, results from two enzymelinked immunosorbent assays (ELISAs) based on the detection of gG-1 or gC-1 were compared for 2,100 serum samples collected during 1999 to 2006.

\section{Methods}

Patients and serum samples

In this study, 1,100 sera from infants, children and adolescents aged o to 18 years, (hereafter referred to as children aged o to 18 years), 800 sera from blood donors aged 19 to 30 years and 200 pregnant women aged between 17 and 40 years were included. These samples had been taken for routine serological tests, for example, medical check-ups or determination of immune status, during 1999 to 2006. For all people whose samples were included, the clinical or laboratory data did not indicate the presence of infectious diseases.

For the blood donors and pregnant women, informed oral consent for use of their sera was obtained. For children aged up to 18 years, consent was not sought. According to the Central Ethical Committee of Germany [16], when residual samples are used for research studies, patient consent is not required in exceptional cases and the effort needed to obtain the consent is not justifiable. In addition, the Ethical Committee of the University of Jena, Germany, approved the study.

Samples from those aged 18 years or under lived in Erfurt, the capital of Thuringia, and its rural surroundings. A total of 844 (76.7\%) of the 1,100 whose samples were selected were healthy and 256 (23.3\%) had adiposity or growth disorders. The anonymised samples were selected by block randomisation from remainders of sera that had been submitted to the laboratory during 1999 to 2006 (770 sera from 1999 to 2000 and 330 sera between 2001 and 2006).
Anonymised sera from the blood donors were selected by block randomisation during 1999 and 2000 from healthy donors living in the region of Erfurt.

Serum samples from the pregnant women were taken from those who delivered at their local district hospital (in Thuringia) between January 1999 and January 2000. The women were enrolled consecutively in the study. All were healthy and routine laboratory parameters were normal.

\section{Testing of sera}

Sera were stored in aliquots at $-20{ }^{\circ} \mathrm{C}$ without interruption until tested for antibodies to HSV-1 and HSV-2. All sera were brought to room temperature immediately before the test was carried out.

Antibody testing was carried out blindly in groups of 90 serum samples. Sera were tested in parallel using HerpeSelect 1 ELISA IgG (Focus Diagnostics, United States), which uses gG-1, and Anti-HSV-1-gC1-ELISA IgG (Euroimmun, Germany) for determination of HSV-1 IgG, as well as HerpeSelect 2 ELISA IgG (Focus Diagnostics, United States) for determination of HSV-2 IgG.

All samples with discordant results in the $\mathrm{gG}-1$ and gC-1 ELISAs were retested twice and the most frequent result (including the original test result) was accepted.

All samples with equivocal results in the $\mathrm{gG}-1$ and $\mathrm{gC}-1$ ELISAs were retested twice. All samples that still gave equivocal results in the gG-1 ELISA after retesting were assessed using immunoblot recomLine HSV-1 \& HSV-2 IgG (Mikrogen, Germany).

All sera with equivocal results in the HSV-2 ELISA were retested twice. Those that still gave equivocal results after retesting were analysed using immunoblot recomLine HSV-1 \& HSV-2 IgG, as were all sera that were positive, to avoid false-positive results, as results from other studies suggests that HSV-2 ELISAs may results in false-positive results [17].

\section{ELISAs}

The HerpeSelect 1 ELISA IgG and HerpeSelect 2 ELISA, which have been licensed by the United States Food and Drug Administration, use recombinant $\mathrm{gG}-1$ and gG-2 antigens, respectively. The sensitivity and specificity of these ELISAs for samples from sexually active adults have been shown to be $91.2 \%$ (HSV-1) to $96.1 \%$ (HSV-2) and 92.3\% (HSV-1) to $97 \%$ (HSV-2) $[18,19]$. All tests were carried out manually. Samples were considered positive if the index value was greater than 1.1. Negative samples had an index value of less than 0.9 and those with index values between 0.9 and 1.1 were considered equivocal. Seroprevalence was calculated only on the basis of the ELISAs using gG-1 and gG-2 and the retest results using an immunoblot assay, where appropriate. 
The Anti-HSV-1-gC1-ELISA IgG uses affinity chromatography-purified $\mathrm{gC}_{1}$ isolated from HSV-1 [15]. Testing of sera was carried out manually. A standard curve based on the extinction values of three calibration sera containing 2, 20 or 200 relative units (RU) per $\mathrm{mL}$ was used to the calculate results. Samples with a cut-off value of $22 \mathrm{RU} / \mathrm{mL}$ or higher were considered positive, $16-22$ $\mathrm{RU} / \mathrm{mL}$ equivocal and below $16 \mathrm{RU} / \mathrm{mL}$ negative. On the basis of the results, we analysed the agreement between the gG-1 and gC-1 ELISAs.

\section{Immunoblot assay}

The immunoblot assay recomLine HSV-1 \& HSV-2 IgG is based on nitrocellulose membranes blotted with purified recombinant gG-1 and gG-2 as well as with proteins common to both types of HSV. The test was performed manually. According to the manufacturers [20], the HSV-1 assay has been shown to have $99 \%$ (in routine diagnostic samples) to $100 \%$ (in samples from blood donors) sensitivity and $88.7 \%$ (routine diagnostics) to $94.6 \%$ (blood donors) specificity. For the HSV-2 immunoblot, the sensitivity was given as $75.0 \%$ (blood donors) to $93.8 \%$ (routine diagnostics) and the specificity as $92.5 \%$ (routine diagnostics) to $100 \%$ (blood donors).

\section{Statistical analysis}

A sample size of about 150 subjects per pre-specified age group was planned to assure that a two-sided $95 \%$ confidence interval $(\mathrm{Cl})$ for the prevalence of HSV antibodies would extend at most $8 \%$ from the observed value for a prevalence range of $5-95 \%$.

Antibody prevalence was calculated using the number of seropositive cases divided by the number of all subjects tested. Assuming a binominal distribution, the two-sided exact $95 \% \mathrm{Cl}$ was calculated.

Differences in antibody prevalence between the sexes, age groups as well as between pregnant women and female blood donors were evaluated by logistic regression odds ratios based on Wald statistics. The level of significance was 0.05 (two-sided). We used SAS V9.2 software for statistical analyses.

The amount of agreement between gG-1 and gC-1 ELISAs was computed using the number of sera with concordant results divided by the number of sera tested.

\section{Results \\ Prevalence of HSV-1 IgG}

Data on the prevalence of IgG antibodies against HSV-1 in the samples tested are shown in Table 1. In the children aged 0-18 years tested, the overall prevalence of antibodies against HSV-1 was $47.6 \%$ (95\% Cl: 44.650.6). During the first year of life, the prevalence was $48.0 \%$ (95\% Cl: 40.9-55.2). It then fell to $19.3 \%$ (95\% $\mathrm{Cl}: 13.3-26.6)$ among those aged $2-3$ years. The prevalence increased to $39.3 \%$ (95\% Cl: $31.5-47.6)$ among the

\section{TABLE 1}

Prevalence of IgG antibodies against HSV-1 in children (aged 0-18 years), adults (blood donors aged 19-30 years) and pregnant women (aged 17-40 years), Thuringia, Germany, 1999-2006 ( $\mathrm{n}=2,100)$

\begin{tabular}{|c|c|c|c|c|c|c|}
\hline \multirow[b]{2}{*}{ Age group in years } & \multicolumn{2}{|c|}{ Male } & \multicolumn{2}{|c|}{ Female } & \multicolumn{2}{|c|}{ Male and female } \\
\hline & $\begin{array}{l}\text { Number of } \\
\text { positive samples/ } \\
\text { total number }\end{array}$ & $\begin{array}{l}\text { Percentage } \\
(95 \% \mathrm{Cl})\end{array}$ & $\begin{array}{c}\text { Number of } \\
\text { positive samples/ } \\
\text { total number }\end{array}$ & $\begin{array}{l}\text { Percentage } \\
(95 \% \mathrm{Cl})\end{array}$ & $\begin{array}{c}\text { Number of } \\
\text { positive samples/ } \\
\text { total number }\end{array}$ & $\begin{array}{l}\text { Percentage } \\
(95 \% \mathrm{Cl})\end{array}$ \\
\hline \multicolumn{7}{|c|}{ Infants, children and adolescents } \\
\hline $0-1$ & $63 / 116$ & $54.3(44.8-63.6)$ & $33 / 84$ & $39.3(28.8-50.5)$ & $96 / 200$ & $48.0(40.9-55.2)$ \\
\hline $2-3$ & $23 / 90$ & $25.6(16.9-35.8)$ & $6 / 60$ & $10.0(3.8-20.5)$ & $29 / 150$ & $19.3(13.3-26.6)$ \\
\hline $4-6$ & $26 / 78$ & $33.3(23.1-44.9)$ & $33 / 72$ & $45.8(34.0-58.0)$ & $59 / 150$ & $39.3(31.5-47.6)$ \\
\hline $7-9$ & $43 / 84$ & $51.2(40.0-62.3)$ & $24 / 66$ & $36.4(24.9-49.1)$ & $67 / 150$ & $44.7(36.6-53.0)$ \\
\hline $10-12$ & $40 / 64$ & $62.5(49.5-74.3)$ & $46 / 86$ & $53.5(42.4-64.3)$ & $86 / 150$ & $57.3(49.0-65.4)$ \\
\hline $13-15$ & $46 / 84$ & $54.8(43.5-65.7)$ & $37 / 66$ & $56.1(43.3-68.3)$ & $83 / 150$ & $55.3(47.0-63.4)$ \\
\hline $16-18$ & $42 / 61$ & $68.9(55.7-80.1)$ & $62 / 89$ & $69.7(59.0-79.0)$ & $104 / 150$ & $69.3(61.3-76.6)$ \\
\hline Total & $283 / 577$ & $49.0(44.9-53.2)$ & $241 / 523$ & $46.1(41.7-50.5)$ & $524 / 1,100$ & $47.6(44.6-50.6)$ \\
\hline \multicolumn{7}{|c|}{ Adults (blood donors) } \\
\hline $19-21$ & $45 / 67$ & $67.2(54.6-78.2)$ & $90 / 133$ & $67.7(59.0-75.5)$ & $135 / 200$ & $67.5(60.5-73.9)$ \\
\hline $22-24$ & $66 / 90$ & $73.3(63.0-82.1)$ & $92 / 110$ & $83.6(75.4-90.0)$ & $158 / 200$ & $79.0(72.7-84.4)$ \\
\hline $25-27$ & $70 / 100$ & $70.0(60.0-78.8)$ & $74 / 100$ & $74.0(64.3-82.3)$ & $144 / 200$ & $72.0(65.2-78.1)$ \\
\hline $28-30$ & $76 / 97$ & $78.4(68.8-86.1)$ & $80 / 103$ & $77.7(68.4-85.3)$ & $156 / 200$ & $78.0(71.6-83.5)$ \\
\hline Total & $257 / 354$ & $72.6(67.6-77.2)$ & $336 / 446$ & $75.3(71.1-79.3)$ & $593 / 800$ & $74.1(70.9-77.1)$ \\
\hline \multicolumn{7}{|l|}{ Pregnant women } \\
\hline $\begin{array}{l}17-40 \\
\text { Total }\end{array}$ & - & - & $164 / 200$ & $82.0(76.0-87.1)$ & - & - \\
\hline
\end{tabular}

HSV: herpes simplex virus. 
4-6 year-olds, to $44.7 \%$ (95\% Cl: $36.6-53.0)$ among the 7-9 year-olds and to $57.3 \%(95 \% \mathrm{Cl}: 49.0-65.4)$ among the 10-12 year-olds. In adolescents aged 13-15 years, $55.3 \%$ (95\% Cl: 47.0-63.4) had been infected; in the $16-18$ year-olds, the prevalence was $69.3 \%$ (95\% $\mathrm{Cl}:$ 61.3-76.6).

The Figure shows the age- and sex-specific prevalence of HSV-1 IgG in the children and adults (blood donors) tested.

Among the blood donors tested, the overall prevalence of HSV-1 IgG antibodies was 74.1\% (95\% Cl: 70.9-77.1). Among those aged $19-21$ years, it was $67.5 \%(95 \% \mathrm{Cl}$ : 60.5-73.9) and increased to values between $72 \%$ (95\%: 65.2-78.1) and $79.0 \%(95 \% \mathrm{Cl}: 72.7-84.4)$ among the 22-30 year-olds.

In the pregnant women tested, the prevalence of HSV-1 IgG was $82.0 \%$ (95\% Cl: 76.0-87.1).

Statistical analysis demonstrated significantly lower prevalence of HSV-1 antibodies in children up to the age of 15 years in comparison with that of the blood donors ( $p<0.001)$. Adjusted for age, the prevalence of HSV-1 antibodies among girls aged between 0 and 18 years was significantly lower than among boys of the same age $(p=0.039)$.

\section{Prevalence of HSV-2 IgG}

The prevalence of antibodies against HSV-2 in the samples tested is shown in Table 2. In the children tested, the overall prevalence was $4.2 \%$ (95\% Cl: 3.1-5.5). In the first year of life, the prevalence was $4.5 \%$ (95\% Cl: 2.1-8.4). In children aged $2-3$ years up to those aged 13-15 years, the lowest value of $2.7 \%$ (95\% Cl: $0.7-6.7)$

\section{FIGURE}

Age- and sex-specific prevalence of IgG antibodies against HSV-1 and HSV-2 in children (aged $0-18$ years) and adults (blood donors aged 19-30 years), Thuringia, Germany, 1999-2006, $(n=1,900)$

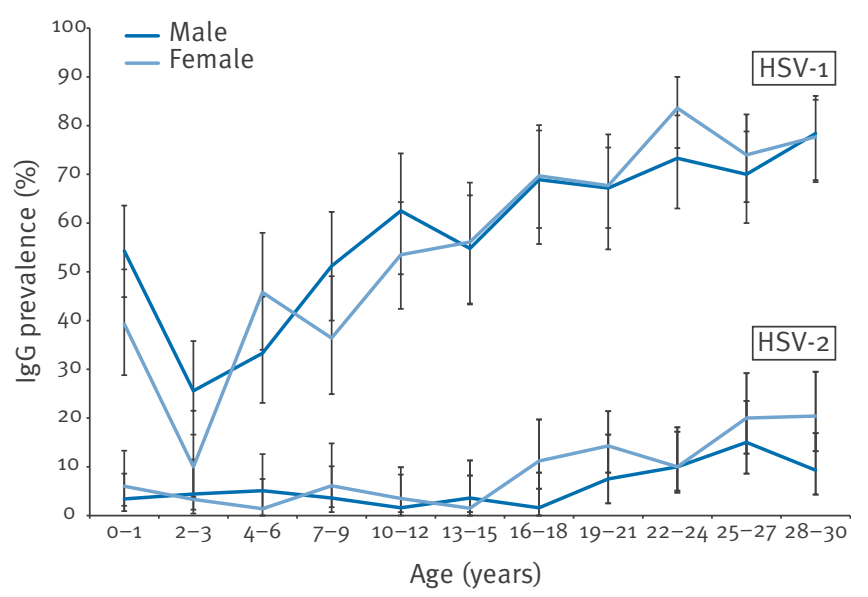

HSV: herpes simplex virus.

The bars show the $95 \%$ confidence intervals for the point estimates. was seen in those aged 10-15 years and the highest, $4.7 \%$ (95\% Cl: 1.9-9.4), in those aged 7-9 years. The prevalence increased to $7.3 \%$ (95\% Cl: 3.7-12.7) among the $16-18$ year-olds and to values between $10.0 \%$ (95\% $\mathrm{Cl}$ : 6.2-15.0) and $17.5 \%$ (95\% Cl: 12.5-23.5) among the 19-30 year-old blood donors, with the lowest value in those aged 22-24 years and the highest in those aged 25-27 years. The age- and sex-specific prevalence of HSV-2 IgG in the children and adults (blood donors) tested is shown in the Figure.

The overall prevalence of HSV-2 IgG was $13.6 \%$ (95\% $\mathrm{Cl}: 11.3-16.2)$ in the blood donors and $18.0 \%(95 \% \mathrm{Cl}$ : 12.9-24.0) in the pregnant women.

Of 191 people who were found to be HSV-2 positive 147 (77.0\%) were coinfected with HSV-1. Only $8 / 46$ (5/26 female and $3 / 20$ male) children $0-18$ years, 26/109 (15/71 female and 11/38 male) blood donors and 10/36 pregnant women were seropositive for HSV-2 alone (data not shown).

Statistical analysis revealed a significantly lower prevalence of HSV-2 IgG in the children (0-18 years) compared with adults (blood donors) (p<0.001). Adjusted for age, a significantly higher prevalence of HSV-2 IgG in women than in men was detected $(p=0.021)$.

\section{Agreement between the HSV-1 gG-1 and} gC-1 ELISAs

Table 3 shows the results of retesting sera that gave discordant or equivocal results using the two HSV-1 ELISAs.

Of the 2,100 sera tested in this study, 71 showed equivocal results in either of the HSV-1 ELISAs after having been repeated twice and were excluded from the comparison of both ELISAs. There was an overall agreement of $97.2 \%(1,973 / 2,029)$ between the results of the $g \mathrm{G}-1$ and $g \mathrm{C}-1$ ELISAs.

When age groups were compared, the agreement between both tests was $95.6 \%(177 / 185)$ in infants aged 0-1 year, $96.7 \%(421 / 435)$ in children aged $2-9$ years, $96.8 \%$ (424/438) in those aged $10-18$ years, $97.9 \%$ (759/775) in the blood donors and 98.0\% (192/196) in the pregnant women.

Of the 40 sera that gave equivocal results in the HSV-1 gG-1 ELISA after having been repeated twice, 37 were negative by immunoblot assay.

\section{Retesting of sera in the HSV-2 ELISA}

Of the 32 sera that gave equivocal results in the HSV-2 gG ELISA, after having been repeated twice, 28 were negative by immunoblot assay (Table 3 ).

After retesting of sera that were positive in the HSV-2 gG-2 ELISA ( $n=201), 191$ (95\%) were also positive in the HSV-2 immunoblot. 


\section{Discussion}

Seroprevalence studies of HSV-1 and HSV-2 are vital for a better understanding of the public health importance of disease due to HSV. In this study, we were particularly interested in determining the HSV seroprevalence of children up to the age of 18 years, since there is little known about this. However, a limitation of the study is that the collection of sera over a seven-year period may mask changes in seroepidemiology.
As expected, the prevalence of antibodies against HSV-1 and HSV-2 was significantly lower in children and adolescents than in adults; however, for HSV-1, this concerned children only up to the age of 15 years. After the disappearance of maternal antibodies in the first year of life, there was an increase in HSV-1 IgG prevalence to $20 \%$ by the age of $2-3$ years, to $40 \%$ by 4-6 years, to almost $60 \%$ by $10-12$ years, to $70 \%$ by 16-18 years and to about $80 \%$ by the age of $28-30$ years. These data add to previous findings from the

\section{TABLE 2}

Prevalence of IgG antibodies against HSV-2 in children (aged 0-18 years), adults (blood donors aged 19-30 years) and pregnant women (aged 17-40 years), Thuringia, Germany, 1999-2006 (n=2,100)

\begin{tabular}{|c|c|c|c|c|c|c|}
\hline \multirow[b]{2}{*}{ Age group in years } & \multicolumn{2}{|c|}{ Male } & \multicolumn{2}{|c|}{ Female } & \multicolumn{2}{|c|}{ Male and female } \\
\hline & $\begin{array}{c}\text { Number of } \\
\text { positive samples/ } \\
\text { total number }\end{array}$ & $\begin{array}{l}\text { Percentage } \\
(95 \% \mathrm{Cl})\end{array}$ & $\begin{array}{c}\text { Number of } \\
\text { positive samples/ } \\
\text { total number }\end{array}$ & $\begin{array}{l}\text { Percentage } \\
(95 \% \mathrm{Cl})\end{array}$ & $\begin{array}{c}\text { Number of } \\
\text { positive samples/ } \\
\text { total number }\end{array}$ & $\begin{array}{l}\text { Percentage } \\
(95 \% \mathrm{Cl})\end{array}$ \\
\hline \multicolumn{7}{|c|}{ Infants, children and adolescents } \\
\hline $0-1$ & $4 / 116$ & $3.4(0.9-8.6)$ & $5 / 84$ & $6.0(2.0-13.3)$ & $9 / 200$ & $4.5(2.1-8.4)$ \\
\hline $2-3$ & $4 / 90$ & $4.4(1.2-11.0)$ & $2 / 60$ & $3.3(0.4-11.5)$ & $6 / 150$ & $4.0(1.5-8.5)$ \\
\hline $4-6$ & $4 / 78$ & $5.1(1.4-12.6)$ & $1 / 72$ & $1.4(0.0-7.5)$ & $5 / 150$ & $3.3(1.1-7.6)$ \\
\hline $7-9$ & $3 / 84$ & $3.6(0.7-10.1)$ & $4 / 66$ & $6.1(1.7-14.8)$ & $7 / 150$ & $4.7(1.9-9.4)$ \\
\hline $10-12$ & $1 / 64$ & $1.6(0.0-8.4)$ & $3 / 86$ & $3.5(0.7-9.9)$ & $4 / 150$ & $2.7(0.7-6.7)$ \\
\hline $13-15$ & $3 / 84$ & $3.6(0.7-10.1)$ & $1 / 66$ & $1.5(0.0-8.2)$ & $4 / 150$ & $2.7(0.7-6.7)$ \\
\hline $16-18$ & $1 / 61$ & $1.6(0.0-8.8)$ & $10 / 89$ & $11.2(5.5-19.7)$ & $11 / 150$ & $7.3(3.7-12.7)$ \\
\hline Total & $20 / 577$ & $3.5(2.1-5.3)$ & $26 / 523$ & $5.0(3.3-7.2)$ & $46 / 1,100$ & $4.2(3.1-5.5)$ \\
\hline \multicolumn{7}{|c|}{ Adults (blood donors) } \\
\hline $19-21$ & $5 / 67$ & $7.5(2.5-16.6)$ & $19 / 133$ & $14.3(8.8-21.4)$ & $24 / 200$ & $12.0(7.8-17.3)$ \\
\hline $22-24$ & $9 / 90$ & $10.0(4.7-18.1)$ & $11 / 110$ & $10.0(5.1-17.2)$ & $20 / 200$ & $10.0(6.2-15.0)$ \\
\hline $25-27$ & $15 / 100$ & $15.0(8.6-23.5)$ & $20 / 100$ & $20.0(12.7-29.2)$ & $35 / 200$ & $17.5(12.5-23.5)$ \\
\hline $28-30$ & 9/97 & $9.3(4.3-16.9)$ & $21 / 103$ & $20.4(13.1-29.5)$ & $30 / 200$ & $15.0(10.4-20.7)$ \\
\hline Total & $38 / 354$ & $10.7(7.7-14.4)$ & $71 / 446$ & $15.9(12.6-19.7)$ & $109 / 800$ & $13.6(11.3-16.2)$ \\
\hline \multicolumn{7}{|l|}{ Pregnant women } \\
\hline $\begin{array}{l}17-40 \\
\text { Total }\end{array}$ & - & - & $36 / 200$ & $18.0(12.9-24.0)$ & - & - \\
\hline
\end{tabular}

HSV: herpes simplex virus.

\section{TABLE 3}

Retesting of sera with discordant or equivocal results in HSV-1 and HSV-2 ELISAs, Thuringia, Germany, 1999-2006

\section{Discordant}

\begin{tabular}{|c|c|c|}
\hline Discordant results between the $\mathrm{gG}-1$ and gC-1 ELISAs (initial test) & $133 / 2,100$ & - \\
\hline Discordant results between the $\mathrm{gG}-1$ and $\mathrm{gC}-1$ ELISAs after repeating the ELISAs twice & $124 / 133$ & - \\
\hline \multicolumn{3}{|l|}{ Equivocal } \\
\hline \multirow{2}{*}{ Equivocal results in the intial ELISA } & HSV-1 gG-1 only & \multirow[b]{2}{*}{$32 / 2,100$} \\
\hline & $40 / 2,100$ & \\
\hline Equivocal results in the ELISA after repeating the ELISA twice & $40 / 40$ & $32 / 32$ \\
\hline Results after retesting by immunoblot assay & $\begin{array}{c}\text { 3/40 positive } \\
37 / 40 \text { negative }\end{array}$ & $\begin{array}{l}\text { 4/32 positive } \\
28 / 32 \text { negative }\end{array}$ \\
\hline
\end{tabular}

ELISA: enzyme-linked immunosorbent assay; g: glycoprotein; HSV: herpes simplex virus.

a Number of sera with the relevant results. A total of 2,100 were initially tested. 
German population, using a relatively small number of sera from infants, children and adolescents [10].

A considerable delay of HSV-1 infection during childhood has been reported from Finland, where only $17 \%$ of children at the age of eight years had antibodies to HSV-1 [21]. Surprisingly, the prevalence of HSV-1 antibodies among girls was lower than among boys in our study. Most studies have not shown significant differences between girls and boys. Our findings are in contrast to the study from Davidovici et al., which demonstrated significantly higher HSV-1 seroprevalence in females aged 10-19 years in Israel [22]. In keeping with the findings from Israel, our study suggests that HSV-1 infection is being acquired later in life. This is in contrast to data from the data from the United States, where $68 \%$ of the population aged over 12 years had HSV-1 antibodies [23], The overall age-specific HSV seroprevalence rates in childhood obtained from Brazil are 1.5 times higher [24] and the figures from Tanzania are two to three times higher [25] than in this study, from one part of Germany. This variation might reflect regional sex-specific differences in exposure to the virus. Since previous infection with HSV-1 may protect against HSV-2 infection or attenuate the severity of disease, lower antibody prevalence among girls may result in a higher number of primary HSV-2 infections that are mostly localised in the genital tract in sexually active individuals. Hence, a reduced incidence of HSV-1 infections during childhood and adolescence, especially in girls, has to be followed up in further HSV-1 seroprevalence studies.

A low prevalence of HSV-2 antibodies of between $2.7 \%$ and $4.7 \%$ was seen in children aged up to 15 years. In those aged $16-18$ years, the prevalence increased to $7.3 \%$, indicating a rising incidence of primary HSV-2 infections, probably due to the start of sexual activity. Our data suggest that between $2.7 \%$ and $4.7 \%$ of all children seem to acquire HSV-2 antibodies in response to intrauterine or neonatal infection. Such infections may be clinically unapparent or not recognised clinically [26]. It should not be forgotten, however, that the low HSV-2 IgG prevalence might also be caused, at least partially, by false-positive test results because of the limited specificity of HSV-2 antibody tests [17]. A review of the literature suggests that the incidence of neonatal diseases caused by both types of HSV ranges widely, from 5 to 31 per 100,000 live births [27]. Relatively high prevalence rates of HSV-2 infection in Tanzanian children suggest that non-sexual transmission of HSV-2 (e.g. person-to-person contact by fingers and hands contaminated with the virus) might also be a reason for HSV-2 seropositivity in childhood [25].

In our study, adults (blood donors) aged between 19 and 30 years had an HSV-2 seroprevalence of $13.6 \%$. There was a significantly higher prevalence of HSV-2specific antibodies among women (16\%) than among men $(11 \%)$ and in pregnant women, the prevalence was $18 \%$. However, the difference in prevalence between pregnant women and female blood donors was statistically not significant. The seroprevalence data of HSV-2 in blood donors in this study are comparable with findings from other parts of Germany [10]. The considerably lower seroprevalence rate of $8.9 \%$ among pregnant women from Stuttgart (Germany) [28] can only be interpreted in the context of the different serological methods used and differences between the populations tested. These factors have also to be considered for the interpretation of data from several countries, where HSV-2 seroprevalence ranged from 4\% (in England and Wales) to $24 \%$ (in Bulgaria) [29].

Our finding of a higher seroprevalence of HSV-2 among women than among men is in agreement with several other studies $[10,30,31]$. This may result from the differential role of sex on clinical presentation since men appear to have a higher tendency of asymptomatic HSV-2 infection [30]. In contrast, infected women are more often symptomatic, which may stop them from having sexual intercourse. This can lead to higher rates of male to female viral transmission.

There is a strong consensus in the literature that tests for HSV type-specific IgG, such as immunoassays or immunoblots that are based on $\mathrm{gG}-1$ and $\mathrm{gG}-2$, are the most accurate for discriminating between infections with HSV-1 or HSV-2 in seroprevalence studies and in serological diagnostics [32-34]. A recent study revealed that $\mathrm{gC}-1$ and $\mathrm{gG}-1$ may be comparable antigenic targets for the serodiagnosis of HSV-1 infections [15]. To our knowledge, the study presented here is the first comprehensive serosurvey that includes both gG-1- and gC-1-based ELISAs. The high level of agreement between the gG-1 and the gC-1 ELISAs, in all age groups, demonstrates a high degree of concordance between reactivities against $\mathrm{gG}-1$ and $\mathrm{gC}-1$. Therefore, the gC-1-specific ELISA appears to be an equivalent alternative to $\mathrm{gG}-1$ tests for the determination of typespecific IgG antibodies against HSV-1.

\section{Conflicts of interest}

S. Schmitt is employed by SanofiPasteur MSD, T. Scheper and S. Saschenbrecker are employed by the Institute of Experimental Immunology (affiliated to Euroimmun AG), and M. Motz and E. Soutschek by Mikrogen.

\section{References}

1. Chayavichitsilp P, Buckwalter JV, Krakowski AC, Friedlander SF. Herpes simplex. Pediatr Rev. 2009;30(4):119-29.

2. Koelle DM, Wald A. Herpes simplex virus: the importance of asymptomatic shedding. J Antimicrob Chemother. 2000;45 Suppl T3:1-8.

3. Smith JS, Robinson NJ. Age-specific prevalence of infection with herpes simplex virus types 2 and 1: a global review. J Infect Dis. 2002;186 Suppl 1:S3-28.

4. Peña KC, Adelson ME, Mordechai E, Blaho JA. Genital herpes simplex virus type 1 in women: detection in cervicovaginal specimens from gynecological practices in the United States. J Clin Microbiol. 2010;48(1):150-3.

5. Morrow RA, Brown ZA. Common use of inaccurate antibody assays to identify infection status with herpes simplex virus type 2. Am J Obstet Gynecol. 2005;193(2):361-2. 
6. Tronstein E, Johnston C, Huang ML, Selke S, Magaret A, Warren $\mathrm{T}$, et al. Genital shedding of herpes simplex virus among symptomatic and asymptomatic persons with HSV-2 infection. JAMA. 2011;305(14):1441-9.

7. Sauerbrei A, Wutzler P. Herpes simplex and varicella-zoster virus infections during pregnancy: current concepts of prevention, diagnosis and therapy. Part 1: herpes simplex virus infections. Med Microbiol Immunol. 2007;196(2):89-94.

8. Rudnick CM, Hoekzema GS. Neonatal herpes simplex virus infections. Am Fam Physician. 2002;6(6):1138-42.

9. Roberts $S$. Herpes simplex virus: incidence of neonatal herpes simplex virus, maternal screening, management during pregnancy, and HIV. Curr Opin Obstet Gynecol. 2009;21(2):124-30.

10. Wutzler P, Doerr HW, Färber I, Eichhorn U, Helbig B, Sauerbrei $A$, et al. Seroprevalence of herpes simplex virus type 1 and type 2 in selected German populations-relevance for the incidence of genital herpes. J Med Virol. 2000;61(2):201-7.

11. Buxbaum S, Geers M, Gross G, Schöfer H, Rabenau HF, Doerr HW. Epidemiology of herpes simplex virus types 1 and 2 in Germany: what has changed? Med Microbiol Immunol. 2003;192(3):177-81.

12. Tunbäck $P$, Bergström T, Claesson BA, Carlsson RM, Löwhagen GB. Early acquisition of herpes simplex virus type 1 antibodies in children-a longitudinal serological study. J Clin Virol. 2007;40(1):26-30.

13. Gupta R, Warren T, Wald A. Genital herpes. Lancet. 2007;370(9605):2127-37.

14. Bergström T, Trybala E. Antigenic differences between HSV-1 and HSV-2 glycoproteins and their importance for type-specific serology. Intervirology. 1996;39(3):176-84.

15. Scheper T, Saschenbrecker S, Steinhagen K, Sauerbrei A, Suer W, Meyer W, et al. The glycoproteins $C$ and $G$ are equivalent target antigens for the determination of herpes simplex virus type 1-specific antibodies. J Virol Methods. 2010;166(1-2):42-7.

16. Zentrale Ethikkommission bei der Bundesärztekammer. Die (Weiter-) Verwendung von menschlichen Körpermaterialien für Zwecke der medizinischen Forschung (2003) [The (further) use of human body samples for the purpose of medical research (2003) English translation of the title]. Berlin: Zentrale Ethikkommission bei der Bundesärztekammer, Berlin [Accessed 15 May 2008]. German. Available from: http://www. zentrale-ethikkommission.de/page.asp?his $=0.1 .21$

17. Ramos S, Lukefahr JL, Morrow RA, Stanberry LR, Rosenthal SL. Prevalence of herpes simplex virus types 1 and 2 among children and adolescents attending a sexual abuse clinic. Pediatr Infect Dis J. 2006;25(10):902-5.

18. Focus Diagnostics. HerpeSelect ${ }^{\circledR} 1$ ELISA IgG. Cypress: Focus Diagnostics. [Accessed 24 Oct 2011]. Available from: http:// www.focusdx.com/pdfs/pi/US/ELo910G.pdf

19. Focus Diagnostics. HerpeSelect ${ }^{\circledR} 2$ ELISA IgG. Cypress: Focus Diagnostics. [Accessed 24 Oct 2011]. Available from: http:// www.focusdx.com/pdfs/pi/US/ELo920G.pdf

20. Mikrogen Diagnostik. recomLine HSV-1 \& HSV-2 IgG. Neuried: Mikrogen Diagnostik. [Accessed 24 Oct 2011]. Available from: http://www.mikrogen.de/uploads/tx_oemikrogentables/ dokumente/GIRLHSDE.pdf

21. Aarnisalo J, Ilonen J, Vainionpää R, Valonen I, Kaitossaari T, Simell O. Development of antibodies against cytomegalovirus, varicella-zoster virus and herpes simplex virus in Finland during the first eight years of life: a prospective study. Scand J Infect Dis. 2003;35(10):750-3.

22. Davidovici BB, Green M, Marouni MJ, Bassal R, Pimenta JM, Cohen D. Seroprevalence of herpes simplex virus 1 and 2 and correlates of infection in Israel. J Infect. 2006;52(5):367-73.

23. Schillinger JA, Xu F, Sternberg MR, Armstrong GL, Lee FK, Nahmias AJ, et al. National seroprevalence and trends in herpes simplex virus type 1 in the United States, 1976-1994. Sex Transm Dis. 2004;31(12):753-60.

24. Clemens SA, Farhat CK. Seroprevalence of herpes simplex 1-2 antibodies in Brazil. Rev Saude Publica. 2010;44(4): 726-34.

25. Kasubi MJ, Nilsen A, Marsden HS, Bergström T, Langeland N, Haarr L. Prevalence of antibodies against herpes simplex virus types 1 and 2 in children and young people in an urban region in Tanzania. J Clin Microbiol. 2006;44(8):2801-7.

26. Marquez L, Levy ML, Munoz FM, Palazzi DL. A report of three cases and review of intrauterine herpes simplex virus infection. Pediatr Infect Dis J. 2011;30(2):153-7.

27. Anizivino E, Fioriti D, Mischitelli M, Bellizzi A, Barucca V, Chiarini $F$, et al. Herpes simplex virus infection in pregnancy and in neonate: status of art of epidemiology, diagnosis, therapy and prevention. Virol J. 2009;6:40.

28. Enders G, Risse B, Zauke M, Bolley I, Knotek F. Seroprevalence study of herpes simplex virus type 2 among pregnant women in Germany using a type-specific enzyme immunoassay. Eur J Clin Microbiol Infect Dis. 1998;17(12):870-2

29. Pebody RG, Andrews N, Brown D, Gopal R, de Melker H, François $\mathrm{G}$, et al. The seroepidemiology of herpes simplex virus type 1 and 2 in Europe. Sex Transm Infect. 2004;80(3):185-91.

30. Langenberg AG, Corey L, Ashley RL, Leong WP, Straus SE. A prospective study of new infections with herpes simplex virus type 1 and type 2. Chirion HSV Vaccine Study Group. N Engl J Med. 1999;341(19):1432-8.

31. Vyse AJ, Gay NJ, Slomka MJ, Gopal R, Gibbs T, MorganCapner $\mathrm{P}$, et al. The burden of infection with HSV-1 and HSV-2 in England and Wales: implications for the changing epidemiology of genital herpes. Sex Transm Infect. 2000;76(3):183-7.

32. Ashley RL, Wu L, Pickering JW, Tu MC, Schnorenberg L. Premarket evaluation of a commercial glycoprotein G-based enzyme immunoassay for herpes simplex virus type-specific antibodies. J Clin Microbiol. 1998;36(1):294-5.

33. Martins TB, Woolstenhulme RD, Jaskowski TD, Hill HR, Litwin CM. Comparison of four enzyme immunoassays with a western blot assay for the determination of type-specific antibodies to herpes simplex virus. Am J Clin Pathol. 2001;115(2):272-7.

34. Sauerbrei A, Wutzler P. Novel recombinant ELISA assays for determination of type-specific IgG antibodies against HSV-1 and HSV-2. J Virol Methods. 2007;144(1-2):138-42. 